The Review of Higher Education

Winter 2012, Volume 35, No. 2, pp. 237-263

Copyright (C) 2011 Association for the Study of Higher Education

All Rights Reserved (ISSN 0162-5748)

\title{
Building a Multicontextual Model of Latino College Enrollment: Student, School, and State-Level Effects
}

\section{Anne-Marie Nuñez and Dongbin Kim}

Latinos are the largest non-White, youngest, and fastest-growing U.S. racial/ethnic population, but their college attainment rates remain the lowest of all groups (Gandara \& Contreras, 2009; Swail, Cabrera, \& Lee, 2004). Meanwhile, policymakers and scholars agree that U.S. postsecondary attainment must rise for the country to maintain its economic advantage (College Board, 2008). Since Latinos are expected to compose over half of

ANNE-MARIE NUÑEZ is an Assistant Professor of Educational Leadership and Policy Studies at the University of Texas at San Antonio. DONGBIN KIM is an Associate Professor of Educational Leadership and Policy Studies at the University of Kansas. Address queries to Anne-Marie Nuñez at the University of Texas at San Antonio, One UTSA Circle, San Antonio, TX 78249-0654; telephone: (310) 428-7827; fax: (210) 458-5848; email: annemarie. nunez@utsa.edu. ACKNOWLEDGEMENTS: This material is based on work supported by the Association for Institutional Research, the National Center for Education Statistics, the National Science Foundation, and the National Postsecondary Education Cooperative under the Association for Institutional Research Grant Number (RG-08-224). Any opinions, findings, and conclusions or recommendations expressed in this material are those of the authors and do not necessarily reflect the views of the Association for Institutional Research, the National Center for Education Statistics, the National Science Foundation, or the National Postsecondary Education Cooperative. The authors express appreciation to the funders of the study and to Amaury Nora, Ana Martinez Aleman, and John Smart, each of whom reviewed various versions of the manuscript in their connection with the Association for the Study of Higher Education Institute on Scholarship and Publishing from an Equity Perspective. 
the college-age population growth within the next decade, raising their postsecondary attainment rates presents one of the most critical policy concerns for improving the overall educational attainment level in the United States (Bowen, Chingos, \& McPherson, 2009).

In recent decades, an increasing number of U.S. high school graduates have enrolled in college directly after high school, but Latino high school graduates' college enrollment rates have remained flat or declined (St. John, 2003; Swail, Cabrera, \& Lee, 2004). According to Bozick and Lauff (2007), 58\% of Latino high school sophomores in 2002, compared with $75 \%$ of White, $82 \%$ of Asian American, and 62\% of African American students, had continued any form of postsecondary education two years after their expected high school graduation. Bowen, Chingos, and McPherson (2009) emphasize that Hispanics' tendency to "undermatch" where they enroll- that is, to enroll in a less selective institution than one for which they are academically qualified-is the primary reason for Hispanics' lower educational attainment rates, since students at less selective institutions graduate at lower rates than those from more selective institutions. Thus, not beginning college at a four-year institution is a key factor limiting Latino students' educational attainment (Arbona \& Nora, 2007; Gandara \& Contreras, 2009).

Limited research exists about influences on college access for students who do not go to college, compared with those who do (Perna, 2006). Latino students' college access is influenced not only by individual characteristics, but also by economic, social, and schooling contexts. In their comprehensive review of research on college access, Perna (2006) and Perna and Thomas (2008) identify four contexts that affect college enrollment, each of which is embedded in the subsequent context: (a) individual student, (b) family, (c) school, and (d) broader social, economic, and political conditions. Among these contexts, Perna and Thomas (2008, p. 32) emphasize students, the schools (K-12 or higher education) they attend, and broader sociopolitical contexts (like state or federal policy environments) as three particularly critical units of analysis. Using a multilevel statistical framework, this study examines the role of student-, school-, and state-level characteristics as influences on Latino students' college enrollment patterns.

\section{Conceptual Model}

College access research initially employed an econometric perspective, emphasizing the impact of financial and human capital on college enrollment (Perna, 2006; Perna \& Thomas, 2008). More recent research has incorporated sociological perspectives emphasizing the role of social, cultural, and structural factors in college enrollment. These factors include social and cultural capital, as well as school, community, higher education, and social, political, 
and historical contextual factors (McDonough, 1997; Perna, 2006; Perna \& Thomas, 2008). Including these variables has added significant predictive power to models of college enrollment (Perna, 2000, 2006).

This study tests a holistic and comprehensive model of college enrollment integrating classic and contemporary college access literature from multiple social science disciplines (Perna \& Thomas, 2008). The model stresses the layered and complex nature of college enrollment and acknowledges that students somewhat determine their own college-going behavior but that their level of individual agency is also embedded in micro-, meso-, and macro-level structural contexts. Perna and Thomas (2008) emphasize that the "three most important units of analysis are students, the K-12 and higher education institutions they attend, and the public policies and programs that shape student and institutional behaviors" (p. 32). Our model therefore identifies three main levels of influence on college access: (a) individual, (b) high school, and (c) social, historical and political context (Perna, 2006; Perna \& Thomas, 2008).

Most previous quantitative studies that examine contextual effects address only two of these units of analysis - the student and the student's high school (e.g., Engberg \& Wolniak, 2010; Perna \& Titus, 2005), or the student and the state policies (e.g., Perna \& Titus, 2004). This study provides a more comprehensive look at the influences on Latino students' college access by addressing all three of these units of analysis. In this first quantitative test of the Perna (2006) and Perna and Thomas (2008) framework as applied to Latino college access, we use three-level hierarchical generalized linear modeling (HGLM) to examine simultaneously the effects of these three key units of analysis on four-year college enrollment: (a) student-level characteristics, including internal and family context factors, (b) high school characteristics, and (c) state-level factors. In the following section, we briefly review the research on factors at different levels that have been found to affect college access for Latinos and for students in general.

\section{Level 1: Student-Level Characteristics}

Student characteristics include students' demographic factors, family context influences, and internal qualities (including educational expectations and academic preparation) (Perna \& Thomas, 2008). In terms of demographic characteristics, male Latinos are less likely to enroll than females (Santiago, 2008). The familial financial situation also influences Latino students' college enrollment; Latino families tend to be misinformed about the costs and benefits of college and more resistant to taking out loans (Dowd, 2008; Kim, 2007). Ethnicity can also affect Latinos' college enrollment tendencies; Mexican American students tend to enroll in less selective institutions than Puerto Ricans, for example (Nuñez, McDonough, Ceja, \& Solorzano, 2008). Immigration generational status can affect K-12 Latinos' academic 
achievement in complex ways (Portes \& Rumbaut, 2001). Students whose first language is not English also face barriers to college access, including inadequate academic preparation (Gandara \& Contreras, 2009; Rodriguez \& Cruz, 2009).

The family context includes parental level of education and access to cultural and social capital (Perna, 2000; Perna \& Titus, 2005). Cultural capital includes access to information about the college application process (McDonough, 1997). In fact, the quantity and quality of access to information about college influences Latino students' college choices more strongly than those of other students (Oakes, Silver, Valladares, Terriquez, \& McDonough, 2006; O'Connor, 2009; O'Connor, Hammack, \& Scott, 2010).

Parental education level can serve as a proxy for a student's access to cultural capital, as it indicates the level of college information a student may have access to within the family (Perna, 2000, 2006; Walpole, 2007). Parental involvement has been considered a measure of social capital, since it represents the potential for social networks and relationships to affect students' college choice (Perna \& Titus, 2005). In addition to the student's own educational expectations, higher parental expectations for the child's postsecondary trajectories can positively affect college enrollment (Walpole, 2007).

With respect to human capital, taking a rigorous high school academic curriculum, particularly higher-level mathematics, is among the strongest determinants of college enrollment and completion (Adelman, 2006). This finding holds when taking into account school- and state-level contextual factors (Perna \& Titus, 2004, 2005). Yet Latino students are too often classified into lower $\mathrm{K}-12$ academic tracks and tend to take lower-level academic courses than other students (Gandara \& Contreras, 2009; Oakes, Silver, et al., 2006)).

\section{Level 2: School-Level Characteristics}

Oakes, Mendoza, and Silver (2006) assert that a school's structural characteristics, curriculum, and the extent to which it has a "college-going" school culture are key factors that affect students' college enrollment. Structural characteristics include demographic characteristics of the school's student body, such as its socioeconomic status level. For example, the percentage of students on a free and reduced price lunch program in a given school has been found to affect academic achievement and college enrollment (Engberg \&Wolniak, 2010; Konstantopoulos, 2006). A school's student-to-teacher ratio is another structural factor that is also related to the quality of a school's teachers and teaching, as it indicates the extent to which students have access to teachers who can offer them personalized guidance (Oakes, Mendoza, \& Silver, 2006). Teacher quality is another important component of the capacity to prepare students for college (Gandara \& Contreras, 2009). According to the No Child Left Behind Act, teacher quality is indicated by the extent 
to which teachers in a school have earned traditional or alternative teaching certificates (Choi, 2010).

A college-going culture involves a school's norms, behaviors, and assumptions related to college preparation and enrollment (Oakes, Mendoza, \& Silver, 2006). In such a culture, school personnel offer students the capacity to meet high educational expectations (Jarsky, McDonough, \& Nuñez, 2009; Oakes, Mendoza, \& Silver, 2006). Since taking a rigorous academic curriculum, particularly in math, strongly predicts college enrollment and completion at the student level (Adelman, 2006), a collectively higher level of math performance may also have a positive effect on the academic culture and human capital of the school. Indeed, higher levels of math course-taking have been found to be positively associated with four-year college enrollment (Engberg \& Wolniak, 2010). Other indicators of a school's college-going culture that affect academic achievement and college enrollment include its attendance rates and the proportion of graduates who attend college (Konstantopoulos, 2006; Perna \& Titus, 2005). The quality and training level of teachers can also affect students' college preparation. Generally, however, schools enrolling larger proportions of Latino students tend to provide fewer academic resources (such as qualified teachers and higher-level classes) to support college-going than schools with larger White enrollments (Gandara \& Contreras, 2009).

\section{Level 3: State-Level Characteristics}

State-level characteristics can be classified into two groups: state context and state policy. State context indicators can include factors related to state history, culture, political makeup, and demographic characteristics, and economic conditions (state poverty rate, unemployment rate) (Martinez, 2002; McLendon \& Hearn, 2007; Perna \& Titus, 2004; Kim \& Rury, 2007). State policy factors found to affect students' college enrollment patterns include the state's funding level for state postsecondary institutions, quality of financial aid for students, and capability of preparing K-12 students for college (Perna \& Titus, 2004). More recent state policy issues with implications for Latinos' college access also involve affirmative action policies and financial aid policies for undocumented students (Gandara \& Contreras, 2009).

Few quantitative studies address state-level influences on college access (Oakes, Mendoza, \& Silver, 2006). Studies tend to examine the influence of school or state level contexts on college enrollment individually (e.g., Perna \& Titus, 2004, 2005), but not both. In this study, we use three-level hierarchical generalized linear modeling (HGLM) to address multiple layers of organizational influence, including school and state contexts, on college access. 


\section{MeTHODS}

\section{Data Sources}

This study drew on multiple data sources to address our research question: What student-, school-, and state-level factors affect Latino high school students' enrollment in a four-year institution? We drew student-level data from the Education Longitudinal Study: 2002 (ELS: 2002), which tracked the postsecondary trajectories of a nationally representative sample of high school students at three time points: when they were sophomores (2002 base year), seniors (2004 first follow-up), and two years after their expected high school graduation date (2006 second follow-up). The base year and first follow-up data addressed students' social, economic, cultural, and academic backgrounds and school experiences; their school characteristics and environment; and their college aspirations. Second follow-up data addressed students' transitions from high school to college, work, and/or other opportunities. ELS data were collected from students and their parents, teachers, and school administrators. Supplementary data came from students' high school transcripts and linked files of the NCES Common Core of Data (CCD).

We also derived school-level data from the ELS: 2002 high school administrators and teachers' survey components. In the base year (2002), NCES conducted separate surveys for school administrators and teachers, in addition to students. These data helped us clarify school effects on college enrollment, including the effects of the school's physical facilities, the academic/ social environment, and teacher quality.

The state-level data were intended to represent a given state's social, economic, and educational environment (Perna \& Titus, 2004; McLendon \& Hearn, 2007). We drew these data mainly from the NCES Digest of Education Statistics (2007) and the state support measures calculated by Trostel and Ronca (2009). Latino students numbered 2,240, comprising about $15 \%$ of the total ELS sample of high school students.

\section{Student-Level Variables}

The dependent variable included two potential outcomes: whether the student had ever enrolled in four-year college versus whether he or she had never enrolled in college within two years of high school graduation. Given the dichotomous nature of the dependent variable, we used HGLM (hierarchical generalized linear model), an extension of the generalized linear model (GLM) that provides estimates of how various factors influence the probability of the occurrence of a binary outcome variable.

Student-level variables included demographic, family context, and internal context variables (Perna \& Thomas, 2008). Demographic factors taken into account were gender (with males as the reference group), ethnicity (Cuban, 
Puerto Rican, Central and South American with Mexican as a reference category), and immigrant generational status. This last variable comprised three categories: (a) first-generation (foreign-born), (b) second-generation students born in the United States with one or two foreign-born parents, and (c) third-generation, with both parents born in the United States (Louie, 2007; Portes \& Rumbaut, 2001). We distinguished between second-generation and third-generation students because students with foreign-born parents might have had different exposure to the U.S. education system or have received different types or amounts of cultural and social capital (observable and unobservable) from their parents than their counterparts with U.S.-born parents. In addition, we examined the effect of students' native language status (Rodriguez \& Cruz, 2009).

For family context characteristics, we included family income, parental education, parental expectations for the student's educational attainment, and parental involvement in the student's educational activities. We examined family income and parental education as distinct indicators of economic and cultural capital (Walpole, 2007). To take into account the potential nonlinear effect of income status, we categorized family income into four levels based on the frequency distribution, with the highest income category as the reference group. We examined parental education level as a proxy for cultural capital, indicating the kind of information about college that parents might be able to pass on to their child (Walpole, 2007). The categories for parental education were first-generation college-goer (neither parent had a bachelor's degree) and continuing-generation (either parent had at least a bachelor's degree).

Parents' educational expectations while the student was in 10th grade represented how far parents expected their student to go in his or her education; these expectations can independently affect college enrollment (Walpole, 2007). Following Perna and Titus (2004), we defined parental involvement as a composite measure of six variables on students' reported frequency of discussing college-related matters with parents in 10th grade. (See Appendix A). Because of research suggesting that Latinos assess finances differently when considering postsecondary options (Kim, 2004, 2007; Dowd, 2008), we also included the parents' perceived ability to pay for college variable, which was a composite of the importance of two measures: the availability of financial aid and how low college expenses were (Engberg \& Wolniak, 2010; Paulsen \& St. John, 2002).

Internal context qualities included a student's educational expectations (reported in the 10th grade), the student's perceived ability to pay for college personally, and his or her academic preparation. A student's educational expectations reflect his or her internal sense of his or her postsecondary possibilities, and thus can condition a student's level of college enrollment (McDonough, 1997). The student's perceived ability to pay for college was based on the student's responses to the same questions asked of parents re- 
garding concerns about finances for postsecondary education. The student's academic preparation level was represented by his or her maximum level of math course-taking (Adelman, 2006). We adapted Burkam and Lee's (2003) scheme and categorized math course-taking as: no or low-level academic, middle-level academic, and advanced math (including pre-calculus and calculus). (See Appendix B for more details on student-level variables.)

\section{School-Level Variables}

School-level variables included structural characteristics and indicators about the school culture with respect to college-going (Oakes, Mendoza, \& Silver, 2006). Structural characteristics included the percentage of students participating in the free and reduced price lunch program and the studentto-teacher ratio. Higher scores on either factor have been shown to correlate negatively to college enrollment (Engberg \& Wolniak, 2010; Konstantopoulos, 2006).

Characteristics reflecting a school's academic and social culture significantly affect college-going rates, even after controlling for students' background characteristics (Bryk \& Thum, 1989; Oakes, Mendoza, \& Silver, 2006; Rumberger, 1995). The average math standardized test scores on the ELS standardized math test served as a measure of collective math preparation at each school. We calculated this score by aggregating the individual values of students within the same school. ${ }^{1}$

Other measures related to a college culture included the school's frequency of absenteeism and percentage of the high school's graduates who enrolled in four-year colleges. Levels of absenteeism indicate the level of commitment of students to their education, and the percentage of graduates who enrolled in four-year colleges suggests the prevalence of expectations and behaviors related to college-going among student peers (Engberg \& Wolniak, 2010; Konstantopoulos, 2006). Lastly, we included the percentage of certified teachers by state criteria as a measure of teacher preparation and quality (Choi, 2010; Gandara \& Contreras, 2009; Oakes, Mendoza, \& Silver, 2006). (See Appendix C for more details on school-level variables.)

\section{State-Level Variables}

State-level data aimed to represent state policy and state context in terms of the social, economic, and educational environment. The work of Trostel

${ }^{1}$ The school-level data in the study were unbalanced, meaning that the number of survey respondents varied at each school. Thus, concerns might be raised about using aggregate composition variables as school characteristics, because the variable scores do not represent the responses of the total population of a school's students. However, our analytic method considered the number of cases within schools when weights were applied at the school-level analysis and is, therefore, an appropriate technique for unbalanced data analysis (Raudenbush \& Bryk, 2002). 
and Ronca (2009) and Perna and Titus (2004) suggests that a state's support of higher education has an independent effect on its patterns of college enrollment. To measure state commitment to higher education in a parsimonious manner, we drew on Trostel and Ronca's recent work (2009) that proposed an integrated measure of state support for postsecondary education. This measure draws on publicly available data to calculate the state's demand for higher education (represented by the number of high school graduates in the state) in relation to the state's ability to pay for this level of demand (represented by the total state funding amount available for postsecondary education) and relative ability to pay for education (represented by the state's per capita income)) (Trostel \& Ronca, 2009, p. 225).

We also examined the effects of variables related to teacher educational and broader economic conditions. The proportion of teachers who have a graduate degree indicated the level of preparation of teachers in that state (Oakes, Mendoza, \& Silver, 2006). The average annual teacher salary in the state's public K-12 schools suggested the economic conditions for teachers. We also included a state's unemployment rate, which can affect rates of college enrollment through determining the availability of job opportunities and the opportunity cost of attending college (Kim \& Rury, 2007; Gandara \& Contreras, 2009; Martinez, 2002). In addition, because Dream Acts—state policies offering undocumented students access to in-state tuition at public institutions-appear to be positively related to Latino students' college enrollment (Flores \& Chapa, 2009), we also examined the effect of whether or not a state had implemented a Dream Act.

Finally, we included an indicator for whether data collected for each state were representative of schools and students in that state. In the ELS study, NCES conducted stratified sampling, in which regions, rather than states, were used to guide selection of high schools for inclusion in the sample. This approach resulted in four states (California, Florida, New York, and Texas) having a representative sample of schools and students; however, the sampling procedure did not ensure that the remainder of the states also had a representative sample. To overcome this limitation, we followed other researchers (Perna \& Titus, 2004) and employed HGLM analysis to examine state-level effects on college enrollment. HGLM's parameter estimation technique can account for unbalanced data within each analysis level and therefore is appropriate for this purpose (Raudenbush \& Bryk, 2002; Raudenbush et al., 2004). Including the representativeness of state data as an independent variable enabled us to clarify further whether having representative data had an independent effect on college enrollment (See Appendix D for more details on state-level variables.) 


\section{Statistical Model}

Individual students are nested within schools, and schools are nested within states. Moreover, there is significant variation among states with respect to legislative policies, the availability of different types of higher education, and social, political, and economic contexts relating to higher education access (Martinez, 2002; McLendon \& Hearn, 2007; Perna \& Titus, 2004). Recognizing the nested structures of the data, this study used threelevel HLM to address the effect of state-level, school-level, and individuallevel characteristics on whether a student enrolled in a four-year college or did not enroll in college at all. Because the dependent variable was binary, this study used hierarchical generalized linear modeling (HGLM), which is an appropriate methodology for a binary outcome variable. We followed Raudenbach and Bryk's (2002) approach to constructing a three-level HGLM.

The first step in any HGLM analysis is to construct a null model (a one-way ANOVA model with random effects) in which no predictors enter into the model. This null model provides an estimated grand mean of the outcome measure and information about the outcome's variance due to betweenschool and between-state differences (Raudenbush \& Bryk, 2002).

$$
\eta_{i j k}=\log \left(\varphi_{i j k} /\left(1-\varphi_{i j k}\right)\right)
$$

In equation $1, \eta_{i j k}$ is the log-odds of attending college. We use $\eta_{i j k}$ as an outcome variable based on the common logistic regression assumption that the relationship of a binary outcome to the predictor variables is linear in the log-odds (Raudenbush \& Bryk, 2002). Equation 1 can be rewritten for probability $\varphi_{i j k}$ as in equation 2 .

$$
\varphi_{i j k}=\frac{1}{1+\exp \left[-\eta_{i j k}\right]}
$$

The next step is constructing a model which specifies a series of studentlevel (Level 1) variables, but which is unconditional at the high school-level (Level 2). Equation 3 estimates differences in the outcome variable attributable to differences in student-level characteristics.

$$
\eta_{i j k}=\beta_{0 j k}+\sum_{q=1}^{Q} \beta_{a j k} X_{a j k}
$$

Equation 3 presents the level 1 structural model. The parameter $\beta_{0 j k}$ is the intercept for the level 1 model predicting log-odds of four-year college enrollment associated with the reference student. $X_{a j k}$ are level-1 coefficients, and $\beta_{a j k}$ is a level-1 predictor $q$ for case $i$ in high school $j$ and state $k$. In this study, only the intercept is specified at a high school-level conditional model (as shown in equation 4). This model uses high-school level variables to explain the variance in four-year college enrollment that is attributable to differences among high schools: 


$$
\beta_{0 j k}=\gamma_{00 k}+\sum_{s=1}^{s_{q}} \gamma_{0 s k} W_{s j k}+u_{0 j k}
$$

Equation 4 presents the level-2 model. $\gamma_{0 j k}$ is a level-2 coefficient and $W_{s i k}$ is a level-2 predictor, and $u_{0 j k}$ is a Level-2 random effect associated with high school $j$ and state $k$.

A Level 3 (i.e., between state-level) conditional model is shown in equation 5. This model includes state-level variables to explain the remaining variance in college enrollment that is attributable to differences among states:

$$
\gamma_{00 k}=\pi_{000}+\sum_{p=1}^{P_{s q}} \alpha_{s a p} \omega_{p k}+u_{00 k}
$$

In this model, $\alpha_{\text {sap }}$ represents the Level 3 coefficient, $\omega_{p k}$ represents the Level-3 predictor, and $u_{00 k}$ represents the Level-3 random effect.

\section{Model Specifications}

The final statistical models for the study were constructed based on the results from our extensive preliminary analyses. Constructing a parsimonious model was particularly crucial, since this study employed a three-level HGLM framework in which model convergence is key. Based on preliminary analyses and past research, we removed a significant number of independent variables from the statistical model to include only the variables known to be more significant to college enrollment as well as variables that did not introduce multicollinearity concerns in our analysis. This approach did not appear to change the results significantly, as the final HGLM model with a reduced number of predictors produced remarkably similar findings to those from our preliminary analyses that included a larger set of variables.

For the HGLM analysis, all the continuous variables at Level 1, Level 2, and Level 3, were centered around their grand mean; this technique controlled for the differences in student and school characteristics across states. No additional centering technique was used for binary variables; binary variables were assumed to be the value of zero when interpreting the intercept terms in the model.

\section{Limitations}

Using three-level multilevel modeling to explore multiple contextual influences on college enrollment presented us with various constraints. Three-level model construction requires a significant degree of parsimony for a model to converge. Thus, we included a limited number of variables in the model based on existing theory and research, and results from our preliminary analyses. Another limitation is that NCES data sets have limited proxies that may not fully reflect the meaning of potentially important factors, including theoretical constructs such as cultural and social capital, or elements of a college-going culture (Perna, 2007). At the state level, quantifying influences 
on educational outcomes is difficult, because of the limited availability of comparable state data elements and proxies for state policy and political considerations (McLendon \& Hearn, 2007).

\section{FiNDINGS}

Table 1 presents the results from the unconditional HGLM model. The expected log-odds of four-year enrollment were equal to 1.164 (in a probability scale $=76.2 \%)$. This means that Latino high school graduates who had the reference category characteristics for categorical variables and the average characteristics for the continuous variables had a $76 \%$ probability of enrolling in four-year institutions. There was significant variability in four-year college enrollment across high schools (level 2), and the variance component (.543) was significant at the .01 level.

On the other hand, we found no significant variance at Level 3 (variance component $=.151, \mathrm{p}$ value $=.145$ ), indicating that the four-year college enrollment rates were not significantly different by states, once all individual and high school characteristics were assumed to be equal.

Although there was no significant variability reported at Level 3, we continued our effort in conducting three-level analysis (meaning that we included random effects at Level 3), because the primary purposes of this study were: (a) to statistically test the three-level conceptual framework developed by Perna (2006) and Perna and Thomas (2008) and (b) to clarify the specific effects of independent variables at individual, high school and state level.

\section{Student-Level Variables}

Table 2 presents the odds ratios of Latino high school graduates enrolling in a four-year college, after controlling for the other variables at Level 1, Level 2, and Level 3. Female Latino students were significantly (about 3.3 times) more likely to enroll in a four-year college than their male counterparts. Latino students from Central and South American countries had twice the odds of enrolling in four-year colleges than their counterpart Mexican students $(\mathrm{p}<.05)$.

As expected, most family context variables representing financial, social, and cultural capital were significant predictors of college enrollment. Latino students from the lower income quadrant (particularly from families earning between $\$ 25,000$ and $\$ 75,000$ ) were significantly less likely to enroll in a fouryear college than their counterparts with higher family incomes of $\$ 75,001$ or more. It is worth noting that Latino students with the lowest family incomes (less than \$25,000) were not statistically different from Latino students with high family income in their odds of going to a four-year institution. We will explore this seemingly counterintuitive relationship later. 
Higher parental educational expectations were associated with increased odds of four-year enrollment by nearly $50 \%$ (odds ratio $=1.492$ ). Parental involvement had a significantly large positive effect on Latino students' college enrollment; students whose parents were more involved in their children's planning for college were $75 \%$ more likely to enroll in a four-year institution. Students with higher educational expectations were just over $40 \%$ more likely to enroll in a four-year institution. Students who had higher concerns about financing college were just over $20 \%$ more likely to have enrolled in a four-year institution.

Taking middle-level and especially advanced mathematics was particularly strongly associated with enrollment in a four-year institution. Latino students who took middle-level math were just over four times as likely to enroll in a four-year institution, compared with not enrolling at all. Latino students who took advanced-level math were about 45 times more likely to enroll in a four-year institution, compared with not enrolling at all.

\section{School-Level and State-Level}

At the school level, two variables emerged as significant predictors for four-year enrollment: percentage of free lunch and absenteeism. Higher levels of free lunch recipients or absenteeism at the school were negatively associated with four-year enrollment. Contrary to expectations, no other school level variables, such as average math standardized test scores or percentage of graduates enrolled in a four-year college, were significant predictors of four-year enrollment.

At the state level, being in a state with a higher proportion of teachers who had graduate degrees was positively associated with Latino students' four-year enrollment. In other words, if Latino students lived in a state where higher percentages of teachers had graduate degrees, they had higher odds of enrolling in four-year institutions than Latino students in other states where lower percentages of teachers had graduate degrees. On the other hand, the average teacher's salary was negatively associated with Latino students' fouryear enrollment. Whether the state data were representative was a significant positive predictor of four-year enrollment. This means that if Latino students lived in the four states where the data collected were representative data (California, Florida, New York, and Texas), these students were more likely to enroll in four-year institutions than students in other states.

\section{Discussion}

This study used quantitative methods to test a model of college enrollment as applied to Latino students. This model specifies that multiple contextual factors, including school and state-level characteristics, condition college enrollment (Perna, 2006; Perna \& Thomas, 2008). Our analysis revealed 
that most of the significant predictors of college enrollment for Latino high school students were at the student level, rather than at the school or state level. This finding is consistent with other research suggesting that individual, rather than school factors, are the primary predictors of college enrollment choices (Engberg \& Wolniak, 2010). However, it is important to emphasize that this study and other research also indicates that the high school context accounts for significant variability in where students go to college, regardless of students' individual characteristics. Collectively, then, rather than suggesting that organizational variables are unimportant in affecting Latino high school students' enrollment in postsecondary education, this research points to the challenges inherent in identifying meaningful organizational variables (in this case, those in high schools and states) that are significantly related to students' postsecondary outcomes (Berger \& Milem, 2000; Engberg \& Wolniak, 2010; McLendon \& Hearn, 2007; Konstantopoulos, 2006).

Among student-level variables, being a Latina female had an independent positive effect on four-year college enrollment. This finding underscores the national disparity between females' and males' college enrollment rates, particularly among Latinos (Laden, Hagedorn, \& Perrakis, 2008; Saenz \& Ponjuan, 2009; Santiago, 2008). Much policy concern has emerged about this issue in recent years, and much remains to be understood about the causes. Family context issues such as different cultural and economic expectations for males and females, local higher education issues such as the availability of local community colleges, and broader social and economic trends of increasing incarceration rates could all be responsible for decreasing Latino males' likelihood of college enrollment (Buchmann, 2009; Long, 2007; Saenz \& Ponjuan, 2009).

Although few studies have addressed ethnic subgroup comparisons in Latino college enrollment (Gandara \& Contreras, 2009; Nuñez, McDonough, Ceja, \& Solorzano, 2008; Torres, 2004), this research suggests that Latino high school students from Central and South American backgrounds are more likely than their Mexican American counterparts to enroll in four-year institutions. These findings reflect concerns about Mexican Americans' relatively low educational attainment rates in comparison to those of other racial/ethnic groups, and remind us that Latino ethnic subgroups have different national backgrounds and immigration histories that condition their educational outcomes (Portes \& Rumbaut, 2001). That is, broader social and economic trends can affect Latino students' educational attainment in different ways, depending on their national origin. Because high school teachers and college personnel sometimes assume that Latino students all have the same national, linguistic, and racial/ethnic background characteristics (Barajas \& Ronnkvist, 2007; Torres, 2004), it is particularly important to understand better how ethnicity conditions Latinos' educational experiences. 
These results suggest that, for Latinos, access to and perceptions about financial capital play a central role in college enrollment. The critical role of financial capital is underscored by the fact that other factors that have been assumed to reflect parents' access to information about college (cultural capital), such as parental education (Walpole, 2007) and native language status (Engberg \& Wolniak, 2010; Perna \& Titus, 2005), did not emerge as significant in this study's findings, holding other variables in the model constant. The relationship between income status and four-year enrollment, however, did not appear to be linear. Being in the middle-income quartiles (having a family income between $\$ 25,000$ and $\$ 75,000)$, compared with being in the upper income quartile (over $\$ 75,000$ ), negatively predicted Latino four-year enrollment. The odds of students in the lowest income quartile (less than $\$ 25,000$ in annual income) enrolling in four-year institutions, however, did not significantly differ from their counterparts who came from the upper income quartile. One possible explanation is that it is difficult to find Latino students from the lowest income group who have the same other individual, school, and state characteristics as high-income Latino students. Such students may have exceptional measures of motivation or other unmeasured characteristics that influence them to enroll in a four-year institution. An alternative explanation is that these students could qualify for larger amounts of financial aid, as programs at very selective private institutions effectively waive tuition for low-income students (Bowen, Chingos, \& McPherson, 2009). These findings could also reflect the possibility that, for Latinos, coming from a higher socioeconomic status group confers less of an advantage than for members of other racial/ethnic groups in predicting four-year college enrollment (O'Connor, 2009; O'Connor, Hammack, \& Scott, 2010).

These findings suggest that, in addition to their families' material resources, students' perceptions and concerns about financing their education affect Latino students' four-year enrollment. That is, Latino students who enroll in four-year institutions are more concerned about their ability to finance their college educations. These findings underscore the importance of offering information about finance to families early in the college planning process and of providing adequate aid to Latino students (Dowd, 2008; Gandara \& Contreras, 2009; Perna, Rowan-Kenyon, Thomas, Bell, Anderson, \& Li, 2008; Rowan-Kenyon, Perna, \& Bell, 2008). Yet with the exception of Indiana's Twenty-first Century Scholars Program and the Gates Millennium Scholarship programs, few college outreach programs incorporate financial support to students during college (Perna, Rowan-Kenyon, Bell, Thomas, \& Li, 2008; St. John, Musoba, \& Simmons, 2003).

In addition to information about financing higher education and (where possible) financial support, hands-on assistance with navigating the actual process of preparing for and applying to college could particularly benefit 
Latino high school students and their families in choosing a four-year college. For example, one recent study suggests that, beyond merely providing students and families with information about applying for financial aid, having students and families work directly with tax professionals to complete Federal Application for Student Financial Aid (FAFSA) forms can increase the likelihood that high school seniors apply for such aid (Bettinger, Long, Oreopoulos, \& Sanbonmatus, 2009).

In general, Latino high school students are less likely than others to receive encouragement from school personnel to pursue four-year higher education (Gonzalez, Stoner, \& Jovel, 2003; Oakes, Silver, et al., 2006). They are also less likely to enroll in advanced math (Bozick \& Lauff, 2007; Gandara \& Contreras, 2009; Oakes, Silver, et al., 2006). This study reinforces the importance of the role that student-level factors of higher student expectations and level of math performance have on four-year enrollment (e.g., Perna, 2000; Perna \& Titus, 2005; Walpole, 2007). Encouraging Latino students to consider four-year colleges and supporting them in taking advanced high school math are important factors that high school counselors and teachers should consciously use to set expectations and prepare students for college.

This study also suggests that elements of the school's structural context and culture affect Latinos' four-year enrollment rates. Attending lower SES schools and schools with higher absenteeism is negatively related to four-year enrollment. Latino high school students attend less well-resourced schools than their high school counterparts, in terms of access to quality teachers, counselors, facilities, and curricula (Gandara \& Contreras, 2009). A high school's access to such resources is reflected in its SES level. It is interesting that other college-related outcomes such as collective average standardized math test scores at the school and the percentage of graduates enrolled in a four-year college did not enter as significant in our analysis. Perhaps these effects were masked by the effects of SES. In any case, this study highlights the importance of ensuring that Latinos' high schools are adequately resourced, which is a challenge in a time when the racial/ethnic and socioeconomic residential segregation of Latinos is actually increasing (Gandara \& Contreras, 2009).

Absenteeism could reflect the extent to which a high school has a college culture, in that it is one indicator of students' commitment to their education, as well as the school's level of enforcing attendance policies. Building on prior findings about the negative effects of higher rates of school-level absenteeism on high school academic achievement (Konstantopoulos, 2006), this study indicates the detrimental effects of increased absenteeism on the longer-term outcome of four-year enrollment. Through signaling limited educational commitment and discipline among students, heightened levels of absenteeism could also compromise a school's capacity to build a college- 
going culture. If absenteeism reflects the college culture of a particular high school, this study suggests that norms and behaviors regarding attendance in school have longer-term educational consequences for students.

Although these findings suggest that, collectively, state-level factors do not account for significant variation in predicting whether Latinos enroll in four-year institutions, there is evidence that some particular state-level characteristics do. The significance of the two state policy variables concerning teachers suggests the important role of teacher quality and training in affecting Latino students' four-year college enrollment, and indicates the importance of this area for policy intervention (Gandara \& Contreras, 2009). First, having more highly qualified teachers in a state (as measured by the proportion of those with certifications) contributes positively to four-year enrollment. Conversely, having more highly paid teachers in a state is negatively related to four-year enrollment. One explanation for the latter, seemingly counterintuitive, finding could be that teachers who have been in the teaching force longer, and thus are more likely to receive higher salaries, may not have teaching certificates that require continuing hours of professional development. Such teachers might not be receiving the training necessary to address Latino students' unique needs in navigating the path to college. These findings suggest that policies seeking to improve teacher quality and training at the state level could make a difference in affecting Latinos' enrollment in four-year institutions.

This study also suggests that living in certain states or regions affects Latino high school students' enrollment in four-year institutions. Our findings suggest that living in highly populated Hispanic states, which also happened to be the states with representative data in the ELS survey (California, Florida, New York, and Texas), contributes positively to the likelihood that Latino high school students will enroll in four-year institutions (O'Connor, Hammack, \& Scott, 2010). These states also have larger public higher education systems, which can provide more geographic and financial postsecondary options for Latino students. Moreover, these states have far higher numbers of four-year Hispanic-Serving Institutions (HSIs), which Latino students often find particularly accessible and welcoming places in which to pursue higher education (Laden, 2001; Santiago, 2007). Moreover, four-year HSIs may offer Latinos additional opportunities to pursue four-year postsecondary education in states where access to public and predominantly White flagship institutions is limited (Perna, Li, Walsh, \& Raible, 2010). How the availability and structure of higher education in local regions and states affects Latino students' college access to four-year institutions merits further research. 


\section{CONCLUSION AND IMPLICATIONS}

This study provides the first quantitative test of a conceptual model addressing how two key contextual levels (high school and state) affect Latino students' college enrollment (Perna, 2006; Perna \& Thomas, 2008). Our study suggests several directions for research, policy, and practice that aim to raise Hispanic educational attainment. First, our findings support other research suggesting that Hispanic males are particularly at risk for not attending college (Santiago, 2008). Future studies need to address a wider range of psychological, cultural, economic, and structural factors that may be contributing to this condition. Understanding how the socialization of Latino males does or does not orient them toward pursuing higher education may inform how interventions can be developed to serve these students more effectively (Buchmann, 2009).

Second, our results point to the importance of recognizing the ethnic diversity within the Latino population and how this diversity influences where Latinos enroll in college (Nuñez, McDonough, Ceja, \& Solorzano, 2008; Torres, 2004). Given the distinct histories of immigrant groups from different countries, more research is needed to address how diverse ethnic backgrounds and patterns of language heritage affect college outcomes (Portes \& Rumbaut, 2001). Such research could inform the development of culturally relevant interventions to promote four-year college enrollment among Latino high school students from diverse backgrounds. Such knowledge is critical, especially when Latino high school students perceive that school personnel do not understand their cultural or linguistic heritage and thus make inappropriate or deficit-oriented assumptions about these students' academic capabilities (Barajas \& Ronnkvist, 2007).

This study highlights the primacy of objective and subjective financial factors in affecting Latino students' college enrollment. For the most part, having a higher family income positively affects Latino students' enrollment in a four-year college, which underscores the importance of access to financial capital in promoting this outcome. Subjective factors about money also come into play; being more concerned about the ability to finance postsecondary education is positively related to four-year enrollment. At the same time, parental involvement is positively associated with four-year enrollment. Interventions that connect material aid with hands-on help in applying for financial aid and that involve both Latino students and their families could be most effective in promoting students' four-year enrollment. It is likely that the most successful interventions will be both the most comprehensive (such as linking $\mathrm{K}-12$ academic achievement with college financial aid) and also the most intrusive, such as having tax professionals complete FAFSA forms alongside Latino parents) (Bettinger, Long, Oreopoulos, \& Sanbonmatus, 2009). 
It is also critical to emphasize the importance of preparing Latino students to take academically rigorous coursework, particularly for four-year enrollment. The odds of attending a four-year institution are much higher for students who have taken advanced math. Yet Latinos tend to be channeled into lower-level coursework (Bozick \& Lauff, 2007; Gandara \& Contreras, 2009; Oakes, Mendoza, \& Silver, 2006). Academic preparation, as well as involving families and students in planning for college course work as early as middle school, must be emphasized to encourage more Latino students to go to college. While rigorous academic preparation clearly ought to be integrated into school practice, programs that link financial incentives and academic preparation, such as Gates Millennium Scholars and Indiana's Twenty-first Century Program, could be particularly effective in encouraging Latino students to go to college (St. John, Musoba, \& Simmons, 2003).

These findings highlight the importance of using P-20 approaches to address Latino high school students' limited access to four-year colleges and universities (Nuñez \& Oliva, 2009; Perna \& Titus, 2005). Although Latino students attend less well-resourced schools than other high school students (Gandara \& Contreras, 2009), Latino high school students benefit from attending more socioeconomically advantaged schools in terms of choosing to enroll in four-year institutions after high school. More careful attention to the distribution and utilization of financial resources in schools that serve significant proportions of Latino students could enhance Latinos' college access. Establishing high school-wide cultural norms in which students are expected to attend and fully engage in their high school classes is also critical, particularly because Latinos may be even more influenced than other high school students by their peers' behavior when choosing colleges (Kim, 2004).

To promote increased Latino enrollment in four-year institutions, states may also have a special role to play in setting standards for teacher quality. This process includes establishing standards for teacher credentialing and professional development in practices that address the needs of Latino and other culturally diverse students (Choi, 2010; Gandara \& Contreras, 2009).

This study indicates that individual and family factors hold the most power in predicting four-year college enrollment, echoing other quantitative research revealing the importance of individual, over and above organizational, factors, in predicting school achievement and college enrollment (Engberg \& Wolniak, 2010; Konstantopoulos, 2006). However, qualitative research has suggested that, at least indirectly, school and state contexts shape how students and their families prepare for college, how they access and interpret information about college, and how they weigh college options (Perna, RowanKenyon, Thomas, Bell, Anderson, \& Li, 2008; Rowan, Perna, \& Bell, 2008). Given the importance of the family in Latino culture (Gandara \& Contreras, 2009; Suarez-Orozco, Suarez-Orozco, \& Todorova, 2008), it could be that the 
effects of students' families as well as their individual characteristics, could be masking factors in school- and state-level contexts that condition college enrollment. Future quantitative and qualitative research ought to address the potential of indirect effects on college enrollment, to examine a broader array of factors affecting college enrollment that were beyond the scope of our study, and to explore more ways of measuring organizational effects on college-going outcomes (Berger \& Milem, 2000).

A critical moment has emerged to address the gap in educational attainment between Latinos and other groups (Bowen, Chingos, \& McPherson, 2009; Gandara \& Contreras, 2009). Unfortunately, this moment coincides with waning state support for public higher education and with general budget shortfalls in the majority of states. The endeavor to close educational attainment gaps will require a substantial investment in academic and financial resources, directed at the student and school levels in various ways. We hope that this and related research on Latinos' educational attainment will inform the use of such resources in creative and fruitful ways.

\section{Appendix A}

\section{Factor Loadings and Reliability Tests FOR FACTORS USED IN THE MODEL}

\begin{tabular}{lr} 
Parental Involvement (original coding: $1=$ never to $3=$ often) & Factor Loadi \\
\hline Discussing school courses with parents & .984 \\
Discussing school activities with parents & .985 \\
Discussing materials studied in class with parents & .990 \\
Discussing grades with parents & .988 \\
Discussing preparation for ACT/SAT with parents & .977 \\
Discussing going to college with parents & .988 \\
Cronbach alpha & $\mathbf{. 9 9 4}$
\end{tabular}

${ }^{a}$ Factor analysis was conducted via Maximum Likelihood Estimation. Only one factor was extracted, and no rotation was conducted.

\section{Appendix B}

Operational Definitions of the Student-LeVel VARIABles In THE ANALYSIS

\begin{tabular}{lll}
\hline Variable & Distribution & Source \\
\hline $\begin{array}{l}\text { College enrollment } \\
\text { (dependent variable) }\end{array}$ & $\begin{array}{l}\text { Not enrolled }=40 \% \text { (reference) } \\
\text { Enrolled in four-year }=60 \%\end{array}$ & F2PS1SEC \\
\hline
\end{tabular}

Gender

Female $=54 \%$

BYS14

Male (reference) group $=42 \%$ 


\begin{tabular}{|c|c|c|}
\hline Variable & Distribution & Source \\
\hline Ethnicity & $\begin{array}{l}\text { Cuban }=8 \% ; \text { Puerto }=13 \% \\
\text { Central \& South }=16 \% \\
\text { Mexican }=63 \% \text { (reference })\end{array}$ & BYHISPAN \\
\hline Immigration status & $\begin{array}{l}\text { 1st generation }=21 \% ; \\
\text { 2nd generation }=43 \% \\
3 \text { rd generation }=46 \%(\text { reference })\end{array}$ & $\begin{array}{l}\text { BYP17, BYP20, } \\
\text { BYP23 }\end{array}$ \\
\hline Language & $\begin{array}{l}\text { Native English speaker }=56 \% \\
\text { Non-native English } \\
\text { speaker }=44 \% \text { (reference) }\end{array}$ & F1STLANG \\
\hline Family income & $\begin{array}{l}\$ 25,000 \text { or less }=27 \% \\
\$ 25,001-\$ 50,000=33 \% \\
\$ 50,001-\$ 75,000=12 \% \\
\text { More than } \$ 75,000=28 \%\end{array}$ & BYP85 \\
\hline Parental education & $\begin{array}{l}\text { Continuing generation } \\
\text { (BA or above) }=32 \% \\
\text { First-generation (less than BA) }=58 \%\end{array}$ & BYPARED \\
\hline $\begin{array}{l}\text { Parental educational } \\
\text { expectations }\end{array}$ & $\begin{array}{l}\text { Mean }=4.42 \\
\text { SD }=1.25 \\
\text { Range }=1 \text { : Less than high school or } \\
\text { high school graduation to 6: M.A., Ph.D., } \\
\text { M.D., or other advanced degree }\end{array}$ & BYPARASP \\
\hline Parental involvement & $\begin{array}{l}\text { Mean }=.29 \\
\mathrm{SD}=.69 \\
\text { Range }=-2.91 \text { to } .67 \text { (factor score) }\end{array}$ & $\begin{array}{l}\text { F1S64A, } \\
\text { F1S64B, } \\
\text { F1S64C, } \\
\text { F1S64E, } \\
\text { F1S64G, } \\
\text { F1S64H }\end{array}$ \\
\hline $\begin{array}{l}\text { Parental perceived } \\
\text { ability to pay }\end{array}$ & $\begin{array}{l}\text { Mean }=2.64 ; \mathrm{SD}=0.69 ; \\
\text { Range }=2 \text { to } 6 \\
\text { Composite measure of two variables: } \\
\text { Postsecondary school's low expenses } \\
\text { are important to parent; Availability } \\
\text { of financial aid is important to parent } \\
\text { (1: not important to 3: very important) }\end{array}$ & $\begin{array}{l}\text { BYP80A } \\
\text { BYP80B }\end{array}$ \\
\hline $\begin{array}{l}\text { Student's educational } \\
\text { expectations }\end{array}$ & $\begin{array}{l}\text { Mean }=4.36 \\
\mathrm{SD}=1.33 \\
\text { Range 1: Less than high school or high } \\
\text { school graduation to 6: M.A., Ph.D., M.D., } \\
\text { or other advanced degree }\end{array}$ & BYSTEXP \\
\hline
\end{tabular}


Appendix B, cont.

\begin{tabular}{|c|c|c|}
\hline Variable & Distribution & Source \\
\hline $\begin{array}{l}\text { Student's perceived } \\
\text { ability to pay }\end{array}$ & $\begin{array}{l}\text { Mean }=4.77 \\
\text { SD }=1.16 \\
\text { Range }=2 \text { to } 6 \\
\text { Composite measure of two variables: } \\
\text { Postsecondary school's low expenses are } \\
\text { important to student; Availability of financial } \\
\text { aid is important to student (1: not important } \\
\text { to 3: very important) }\end{array}$ & $\begin{array}{l}\text { FY1S52A } \\
\text { F1S52B }\end{array}$ \\
\hline $\begin{array}{l}\text { Math course-taking } \\
\text { (maximum level of } \\
\text { coursework) }\end{array}$ & $\begin{array}{l}\text { No or low level math }=14 \% \text { (low or no } \\
\text { math courses, including algebra } 1 \text { and } \\
\text { geometry; reference category) } \\
\text { Middle level math }=42 \% \text { (algebra } 2, \\
\text { advanced trigonometry, probability or } \\
\text { statistics, or algebra } 3 \text { ) } \\
\text { Advanced math }=45 \% \text { (precalculus } \\
\text { or calculus) }\end{array}$ & F1RMAPIP \\
\hline
\end{tabular}

\section{Appendix C}

\section{Operational Definitions of the School-Level} Variables In THE ANALYsis

\begin{tabular}{lll}
\hline Variable & Distribution & Source \\
\hline \% free lunch & Mean $=26.64$ & CPO4FLUN \\
& SD $=16.77$ & \\
Range $=0-84.44$ & CPO3STRO \\
Student: teacher ratio & Mean $=17.44$ & \\
& SD $=4.54$ & \\
Range $=7.21-39.09$ & School average from \\
Mean value of math & Mean $=49.72$ & student-level variable \\
standardized test & SD $=5.25$ & (F1TXMSTD) \\
scores & Range $=37.78-64.03$ & BYA49B \\
Absenteeism & Mean $=4.79$ & \\
(1 = never happens to & SD $=1.08$ & F1A19A \\
$5=$ happens daily) & Range $=1-5$ & \\
Percentage of 2003 & Coding scheme: $1:$ none, 2:1-10\%, & \\
graduates who went & $3: 11-24 \%, 4: 25-49 \%, 5: 50-74 \%$, & \\
to four-year college & $6: 75-100 \%$ & \\
& Mean $=4.44$ & \\
& SD $=1.08$ & \\
& Range $=2-6$ & \\
Percentage of & Mean $=91.21$ & \\
certified teachers & SD $=17.83$ & \\
& Range $=0-100$ & \\
\hline
\end{tabular}




\section{Appendix D}

\section{Operational Definitions of the State-LeVel Variables in THE ANALYSIS}

\begin{tabular}{lll}
\hline Variable & Distribution & Source \\
\hline State support & Mean $=0.19$ & Trostel \& Ronca, 2009 \\
& SD $=0.06$ & \\
Range $=0.10-0.37$ & NCES (2007), Table 66 \\
$\begin{array}{l}\text { Proportion of public } \\
\text { school teachers who } \\
\text { have graduate degrees }\end{array}$ & $\begin{array}{l}\text { Mean }=47.87 \\
\text { Range }=27.00-78\end{array}$ & \\
$\begin{array}{l}\text { Average annual } \\
\text { teacher salary }\end{array}$ & Mean $=37,850$ & NCES (2007), Table 73 \\
& SD $=5,490$ & \\
Unemployment rate & Range $=31,190-51,210$ & \\
& Mean $=5.39$ & U.S. Census (2006), \\
& SD $=.89$ & Table A-29 \\
State representativeness & Range $=3.40-7.60$ & \\
of the data & Yes $=9 \%$ & BYA34A in the ELS: \\
State has Dream Act & Yes $=16 \%$ & 2002 data \\
& No $=84 \%$ & Flores \& Chapa, 2009 \\
\end{tabular}

\section{REFERENCES}

Adelman, C. (2006). The toolbox revisited: Paths to degree completion from high school through college. Washington, DC: U.S. Department of Education.

Arbona, C., \& Nora, A. (2007). The influence of academic and environmental factors on Hispanic college degree attainment. The Review of Higher Education, 30(3), 247-270.

Barajas, H. L., \& Ronnkvist, A. (2007). Racialized space: Framing Latino and Latina experience in public schools. Teachers College Record, 109(6), 1517-1538.

Berger, J. B., \& Milem, J. F. (2000). Organizational behavior in higher education and student outcomes. In J. C. Smart (Ed.), Higher education: Handbook of theory and research (Vol. 15, pp. 268-338). New York: Agathon Press.

Bettinger, E. P., Long, B. T., Oreopoulos, P., \& Sanbonmatus, L. (2009). The role of simplification and information in college decisions: Results from the HひR Block FAFSA experiment. Cambridge, MA: National Bureau of Economic Research Working Paper 15361.

Bowen, W., Chingos, M., \& McPherson, M. (2009). Crossing the finish line. Princeton, NJ: Princeton University Press.

Bozick, R., \& Lauff, E. (2007). Educational Longitudinal Study of 2002 (ELS: 2002): A First Look at the Initial Postsecondary Experiences of the High School Sophomore Cohort of 2002. Washington, DC: National Center for Education Statistics.

Bryk, A. S., \& Thum, Y. M. (1989). The effects of high school organization on dropping out: An exploratory investigation. American Educational Research Journal, $26,353-383$. 
Buchmann, C. (2009). Gender inequalities in the transition to college. Teachers College Record, 111(10), 2320-2346.

Burkam, D., \& Lee, V. (2003). Mathematics, foreign language, and science coursetaking and the NELS: 88 Transcript Data. Washington, DC: National Center for Education Statistics Working Paper.

Choi, D. C. (2010). The impact of competing definitions of quality on the geographical distribution of teachers. Educational Policy, 24(2), 359-397.

College Board. (2008). Coming to our senses: Education and the American future. New York: Author.

Dowd, A. (2008). Dynamic interactions and intersubjectivity: Challenges to causal modeling in studies of college student debt. Review of Educational Research, $78(2), 232-259$.

Engberg, M. E., \& Wolniak, G. C. (2010). Examining the effects of high school contexts on postsecondary enrollment. Research in Higher Education, 51, 132-153.

Flores, S. M., \& Chapa, J. (2009). Latino immigrant access to higher education in a bipolar context of reception. Journal of Hispanic Higher Education, 8(1), 90-109.

Gandara, P., \& Contreras, F. (2009). The Latino education crisis: The consequences of failed social policies. Cambridge, MA: Harvard University Press.

Gonzalez, K., Stoner, C., \& Jovel, J. (2003). Examining the role of social capital in access to college for Latinas: Toward a college opportunity framework. Journal of Hispanic Higher Education, 2(2), 146-170.

Jarsky, K., McDonough, P., \& Nuñez, A-M. (2009). Establishing a college culture in secondary school through P-20 collaboration: A case study. Journal of Hispanic Higher Education, 8(4), 357-373.

Kim, D. (2004). The effect of financial aid on students' college choice: Differences by racial groups. Research in Higher Education, 45(10), 43-70.

Kim, D. (2007). The effect of loans on students' degree attainment: Differences by student and institutional characteristics. Harvard Educational Review, 77(1), 64-100.

Kim, D., \& Rury, J. (2007). The changing profile of college access: The Truman Commission and enrollment patterns in the postwar era. History of Education Quarterly, 47(3), 302-327.

Konstantopoulos, S. (2006). Trends of school effects on student achievement: Evidence from NLS: 72, HSB: 82 and NELS: 92. Teachers College Record, 108(12), 2550-2581.

Laden, B. V. (2001). Hispanic-serving institutions: Myths and realities. Peabody Journal of Education, 76(1), 73-92.

Laden, B. V., Hagedorn, L. S., \& Perrakis, A. (2008). Donde estan los hombres?: Examining success of Latino male students at Hispanic-serving community colleges. In M. Gasman, B. Baez, \& C.S.V. Turner (Eds.), Understanding minority-serving institutions (pp. 127-140). Albany: State University of New York Press.

Long, B. (2007). The reversal of the college gender gap: The role of alternatives and college supply. Cambridge, MA: National Bureau of Economic Research.

Louie, V. (2007). Immigrant newcomer populations, ESEA, and the pipeline to college: Current considerations and future lines of inquiry. Review of Research on Education, 29, 69-105. 
Martinez, M. C. (2002). Postsecondary enrollment and state policy: Meeting the future demand. Sterling, VA: Stylus.

McDonough, P. M. (1997). Choosing colleges: How schools and social class structure opportunity. Albany: State University of New York Press.

McLendon, M. K., \& Hearn, J. C. (2007). Incorporating political indicators into comparative state study of higher education policy. In D. E. Heller \& K. E. Shaw (Eds.), State postsecondary education research: New methods to inform policy and practice (pp. 11-36). Sterling, VA: Stylus.

NCES. National Center for Education Statistics (2007). Digest of Education Statistics: 2007. Washington, DC: Author.

Nuñez, A.-M., McDonough, P., Ceja, M., \& Solorzano, D. (2008). Diversity within: Latino college choice and ethnic comparisons. In C. Gallagher (Ed.), Racism in Post-race America: New theories, new directions (pp. 267-284). Chapel Hill, NC: Social Forces Publishing.

Oakes, J., Mendoza, J., \& Silver, D. (2006). California opportunity indicators: Informing and monitoring progress California's progress toward equitable college access. In P. Gandara \& G. Orfield (Eds.), Expanding opportunity in higher education: Leveraging promise (pp. 19-52). Albany: State University of New York Press.

Oakes, R. J., Silver, D., Valladares, S., Terriquez, V., \& McDonough, P. (2006). Removing the roadblocks: Fair college opportunities for all California students. Los Angeles: UC All Campus Consortium for Research on Diversity and UCLA Institute for Democracy, Education, and Access.

O'Connor, N. (2009). Hispanic origin, socio-economic status, and community college enrollment. The Journal of Higher Education, 80(2), 121-145.

O'Connor, N., Hammack, F. M., \& Scott, M. A. (2010). Social capital, financial knowledge, and Hispanic student college choices. Research in Higher Education, 51(1), 195-219.

Nuñez, A-M., \& Oliva, M. (2009). Organizational collaboration to promote college access: A P-20 framework. Journal of Hispanic Higher Education, 8(4), 322-339.

Paulsen, M. B., \& St. John, E. P. (2002). Social class and college costs: Examining the financial nexus between college choice and persistence. Journal of Higher Education, 73(3), 189-236.

Perna, L. W. (2000). Differences in the decision to attend college among African Americans, Hispanics, and Whites. Journal of Higher Education, 71(2), 117-141.

Perna, L. W. (2006). Studying college access and choice: A proposed conceptual model. In J. Smart (Ed.), Higher education: Handbook of theory and research (Vol. 21, pp. 99-1157). Cambridge, MA: Springer.

Perna, L. W. (2007). The sources of racial-ethnic group differences in college enrollment: A critical examination. In F. K. Stage (Ed.), Using quantitative data to answer critical questions (pp. 51-66). San Francisco: Jossey-Bass.

Perna, L. W., Li, C., Walsh, E., \& Raible, S. (2010). The status of equity for Hispanics in public higher education in Florida and Texas. Journal of Hispanic Higher Education, 9(2), 145-166. 
Perna, L., Rowan-Kenyon, H. T., Bell, A., Thomas, S. L., \& Li, C. (2008). A typology of federal and state programs designed to promote college enrollment. The Journal of Higher Education, 79(3), 243-267.

Perna, L. W., Rowan-Kenyon, H. T., Thomas, S. L., Bell, A., Anderson, R., \& Li, C. (2008). The role of college counseling in shaping opportunity: Variations across high schools. Review of Higher Education, 31(2), 131-159.

Perna, L. W., \& Thomas, S. L. (2008). Theoretical perspectives on student success: Understanding the contributions of the disciplines. ASHE/ERIC Higher Education Report, 34(1), San Francisco: Jossey-Bass.

Perna, L. W., \& Titus, M. A. (2004). Understanding differences in the choice of college attended: The role of state public policies. Review of Higher Education, 27(4), 501-526.

Perna, L. W., \& Titus, M. A. (2005). The relationship between parental involvement as social capital and college enrollment: An examination of racial/ethnic group differences. Journal of Higher Education, 76(5), 486-518.

Portes, A., \& Rumbaut, R. (2001). Legacies: The story of the immigrant second generation. New York: Russell Sage.

Raudenbush, S., \& Bryk, A. (2002). Hierarchical linear models: Applications and data analysis methods (2nd ed.). Thousand Oaks, CA: Sage Publications.

Raudenbush, S. W., Bryk, A. S., Congdon, R. (2004). HLM: Hierarchical Linear and Nonlinear Modeling. HLM software.

Rodriguez, G., \& Cruz, L. (2009). The transition to college of English learner and undocumented immigrant students: Resource and policy implications. Teachers College Record, 111(10), 1119-1152.

Rowan-Kenyon, H. T., Perna, L. W., \& Bell, A. (2008). Contextual influences on parental involvement and college-going: Variations by socioeconomic class. Journal of Higher Education, 79(5), 564-586.

Rumberger, R. W. (1995). Dropping out of middle school: A multilevel analysis of students and schools. American Education Research Journal, 32, 562-583.

Saenz, V. B., \& Ponjuan, L. (2009). The vanishing Latino male in higher education. Journal of Hispanic Higher Education, 8(1), 54-89.

Santiago, D. A. (2007). Voces (Voices): A Profile of Today's Latino College Students. Washington, DC: Excelencia in Education.

Santiago, D. A. (2008). The condition of Latinos in education: 2008 fact book. Washington, DC: Excelencia in Education.

St. John, E. P. (2003). Refinancing the college dream: Access, equal opportunity, and justice for taxpayers. Baltimore: Johns Hopkins University Press.

St. John, E. P., Musoba, G. D., \& Simmons, A. B. (2003). Keeping the promise: The impact of Indiana's twenty-first century scholars program. The Review of Higher Education 27(1), 103-123.

Suarez-Orozco, C., Suarez-Orozco, M., \& Todorova, I. (2008). Learning a new land: Immigrant students in American society. Cambridge, MA: Belknap.

Swail, W. S., Cabrera, A. F., \& Lee, C. (2004). Latino youth and the pathway to college. Washington, DC: Educational Policy Institute. 
Torres, V. (2004). The diversity among us: Puerto Ricans, Cuban Americans, Caribbean Americans, and Central and South Americans. In A. M. Ortiz (Ed.), New Directions for Student Services (Vol. 105, No. 16, pp. 5-15). San Francisco: Jossey-Bass.

Trostel, P., \& Ronca, J. M. (2009). A simple unifying measure of state support for postsecondary education. Research in Higher Education, 50, 215-247.

U.S. Census. (2006). State and metropolitan area databook. Washington, DC: Author.

Walpole, M. B. (2007). Economically and educationally challenged students in higher education: Access to outcomes. ASHE-Higher Education Report Series, 33(3), 1-113. 